\title{
A Fuzzy Logic Controller to Minimize the Effect of Input Temperature Fluctuations on the Deviation of Relative Humidity to Avoid Instrument's Deterioration
}

\author{
Avnesh Verma, Vishnu Anand Tiwari
}

\begin{abstract}
A fuzzy Logic Inference System (FIS) has been designed for decision making regarding the values of relative humidity and temperature associated with it. The fuzzy logic controller has been designed to minimize the effect of input temperature fluctuations on the deviation of relative humidity. The relative humidity has two input components and one output Mamdani fuzzy controller. The results obtained after fuzzification is tested in Simulink and the response is compared with the response obtained from the conventional PID controller. In PID controller controlled instrument there was very large peak overshoot. The step response of this system shows first peak overshoot of around $67 \%$ and a finite amount of steady state error persists. The fuzzy PID controller shows though it is slower than conventional PID controller but peak overshoot is almost reduced to zero level so the effect of input temperature fluctuations will not be able to affect the relative humidity and the performance of the instrument will be improved substantially. From the result it can be easily observed that Fuzzy controller can efficiently reduce the oscillations and produces smooth response.
\end{abstract}

Keywords - Fuzzy Logic inference System; (FIS), Temperature Humidity Index; (THI), fuzzy analysis, PID; (Proportional Integral Derivative) controller, Rule Viewer, $\mathrm{R} / \mathrm{H}$ generator and calibrator.

\section{INTRODUCTION}

Fuzzy Logic inference System (FIS) has decision making capabilities with its inherent ability to work with 'IF... THEN' rules along with 'OR' or 'AND' . FIS acts as brain of the entire system as it always produces fuzzy set outputs. It can convert fuzzy variables into crisp variables during its defuzzification operations. When it is acting as fuzzy controller it generates fuzzy outputs inevitably. In our earlier study fuzzy rules were established. The fuzzy sets explicitly producing the comparable results from rule base, data base,

Manuscript revised June 9, 2019 and published on July 10, 2019

Avnesh Verma, Department of Instrumentation, Kurukshetra University Kurukshetra-136119, Haryana, India.

Vishnu Anand Tiwari, Department of Instrumentation ${ }^{2}$, National Institute of $^{2}$ Technology, Kurukshetra-136119, Haryana, India. decision making, fuzzification inference unit etc [1]. Moving forward with our earlier study we have precisely built up FIS to obtain the desired response. In our previous fuzzy analysis the temperature humidity index (THI) depends upon temperature and relative humidity as independent variables were analyzed. Four categories such as Normal, Alert, Extreme and Prohibited were defined. The first three operates depending upon instrument's accuracy and precision. But the fourth condition is not operative and necessary changes in environmental conditions are required to make instrument operational [1].

In this paper a fuzzy logic controller has been proposed which is used to minimize the effect of input temperature fluctuations on the deviation of relative humidity. As relative humidity is the variance of water vapor content in air communicated as a level of the sum required for immersion at a similar temperature. So, if temperature will keep changing with frequently the relative humidity will get affected. As a result instrument's performance get degraded.

\section{LiterATURE REVIEW}

M.R. Mohanraj, M. Balamurugan, V. P. Suresh, and R. Gobu, provide more economical, comfortable, reliable \& effective controls and they are feasible in real operating room. Mamdani-type and Sugeno-type fuzzy models are two types of Fuzzy Inference Systems (FIS) are compared [2]. Tarun Kumar Das, Yudhajit Das explained the ideal relative humidity level for user's set temperature is controlled using fuzzy logic control systems in process automation with potential benefits [3]. K.A. Akpado, P. N. Nwankwo, D.A Onwuzulike, M.N. Orji, has developed a Fuzzy logic controller (FLC) to maintain temperature and humidity at set conditions [4]. K. Ramesh, A. P. Kesarkar, J. Bhate, M. Venkat Ratnam, A. Jayaraman, concludes that retrieved profiles using ANFIS techniques have improved the temperature retrievals substantially [5]. O. Zadehbagheri, H. Eskandari, A. Rezazadeh, M. Sedighizadeh, presents a paper it states that fuzzy type- 2 produces better results than the other techniques on this system [6].

\section{IMPLEMENTATION OF SIMULINK IN FUZZY CONTROLler}

The Fuzzy Logic Inference System (FIS) is designed to work seamlessly with Simulink, for analyzing the response obtained by the fuzzy controller. Once we have created our fuzzy inference system using graphical user interface or by any other method, it can be directly embed this FIS for 
simulation to obtain the response. The steps of implementation of fuzzy controller with Simulink with the help of fuzzy logic controller with rule viewer and membership function $[7,8]$.

The Fuzzy Logic Controller with Rule Viewer block is an extension of the Fuzzy Logic Controller block. It allows you to visualize how rules are fired during simulation as shown in figure 1 .

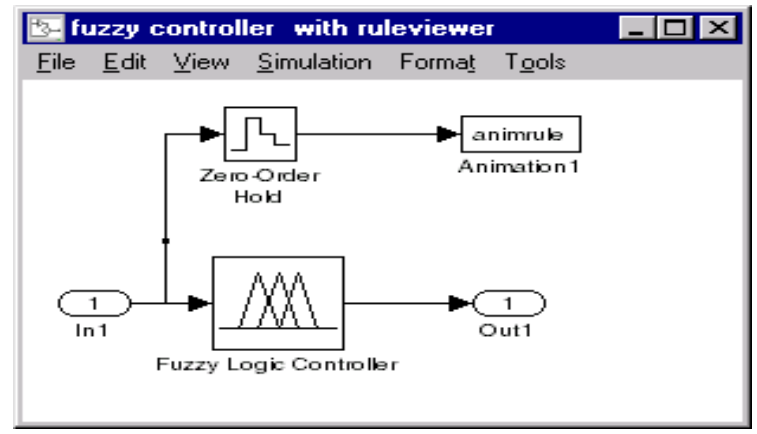

Fig. 1. Fuzzy controller with rule viewer.

For most fuzzy inference systems, the Fuzzy Logic Controller automatically generates a hierarchical representation of our FIS. The Fuzzy wizard is automatic model generation ability. The FIS allows for efficient code generation. The Fuzzy Wizard cannot handle FIS with custom membership functions or with AND, OR, IMP, and AGG functions other than [7] the following list:

- OR Method: max

- AND Method: min, prod

- Imp Method: min, prod

- Aggregation Method: max

\section{A. Data acquisition for fuzzy analysis}

It works on the principle of Dalton's law of partial pressure (two pressure technique). It utilizes nitrogen gas or air. The system consists of two chamber namely saturator having distilled water and a test chamber. The carrier gas stream at an elevated pressure is supplied to a saturator, which is expanded to a lower pressure through an expansion device into a test chamber. The ratio of two absolute pressures and the measurement of dry bulb temperature in the test chamber provide the desired dew point or relative humidity. In this device a stand mounted closed saturator chamber provided with a temperature sensor, pressure measuring device, water level indicator and a tubular coil (heat exchanger) having an external inlet and an internal bottom nozzle opening, the said tubular coil being also provided with a bottom gas distribution plate, the closed top end of the saturator chamber being interconnected to the bottom of a closed test chamber through an interconnecting gas expansion assembly, the said test chamber being provided with a temperature sensor, a pressure sensor, a gas outlet and a capacitance type hygrometer.

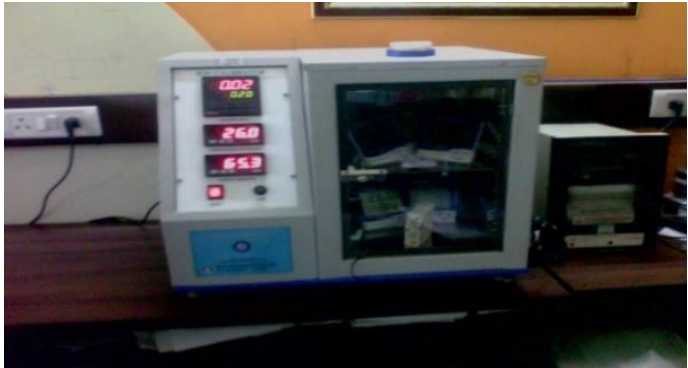

Fig. 2. R/H Generator and Calibrator

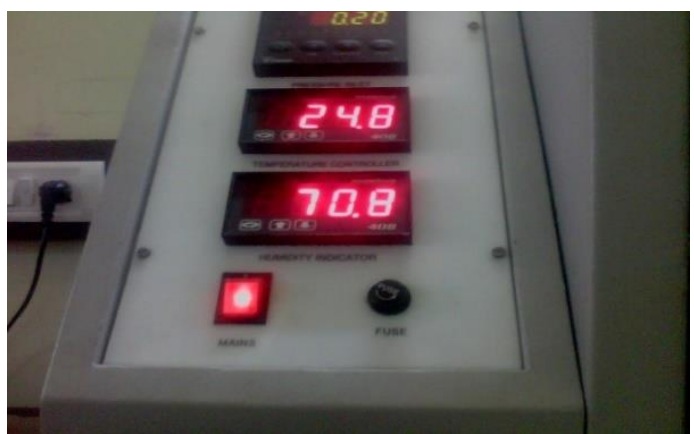

Fig.3. Readings of R/H Generator and Calibrator

The major source of data acquisition for this research work is the $\mathrm{R} / \mathrm{H}$ generator and calibrator technology transfer by NPL $[9,10]$.

According to the tolerance band of instrument this THI was categorized in four groups as: Normal, Alert, Extreme and Prohibited. Up to the first three zone the instrument can be operated depending upon need of accuracy of instrument but $4^{\text {th }}$ zone is non operable zone where the instrument can't work. These category represent another kind of variables which can be recognized as linguistic variables. These linguistic variables are now used to analyze through the fuzzy set theory. The linguistic variable was tabulated as

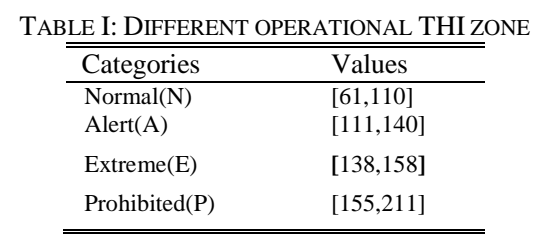

\section{Fuzzy Controller Modeling}

\section{A. Central Idea}

A fuzzy logic controller has been proposed to minimize the effect of input temperature fluctuation on the relative humidity a two input and 1 output Mamdani fuzzy controller is taken whose input parameters are temperature and rate of change of temperature. The result obtained after fuzzification is tested in Simulink and the response is compared with the response obtained from the conventional PID controller working in the instrument. From the comparative study of both the results it is clearly shown the advantage of fuzzy controller over conventional PID controller which is currently being used in the instrument [8]. 


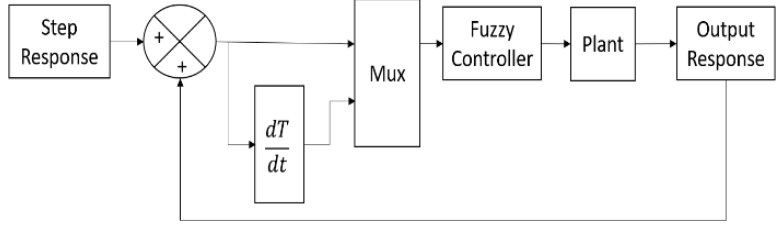

Fig. 4. Block Diagram of proposed controller.

\section{B. Fuzzy logic controller using Simulink}

Fuzzy Logic Control (FLC) has excelled in dealing with systems that are complex, non-linear or time-varying. FLC is moderately simple to actualize, as it is normally needs no logical model of the control system. Fuzzy logic has quickly turned out to be a most present advancements for creating refined control systems and generate exact arrangements from certain or surmised data [9].

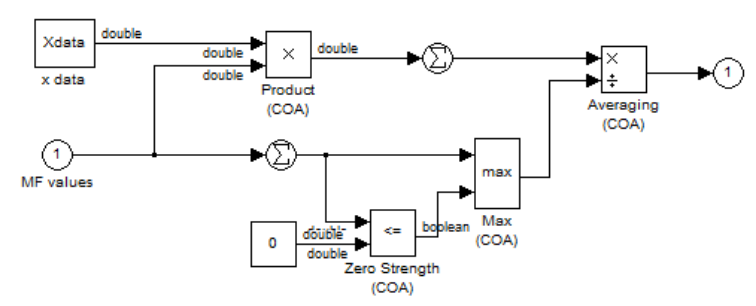

Fig. 5. Block Diagram of proposed controller

Step response of the system is obtained. The inputs of fuzzy controller are temperature and rate of change of temperature and the output is given to the plant whose response can be seen in the scope.

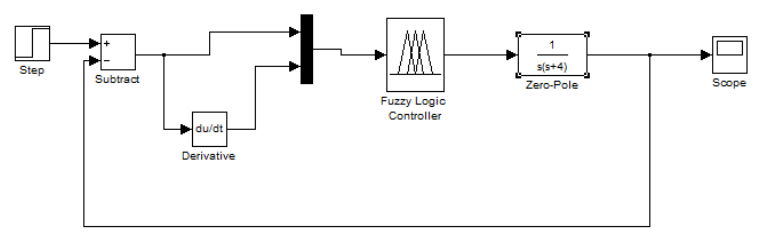

Fig. 6. Simulation setup for proposed fuzzy controller

\section{Membership function}

In temperature and humidity control it is suitable to choose Gaussian shape, but if Gaussian shape will be chosen for its membership function the distribution fuzzy variable operation will become quite complex and calculated speed will be slow down. As the triangular membership function is also similar to Gaussian membership function as well as relatively simpler also so for the computation to be relatively simple, in this research triangular shape has been used for all the membership function of input and output variables. For relative humidity 10 membership function has been defined from $\mathrm{H} 1$ to $\mathrm{H} 10$ with relative humidity varying from $0 \%$ to $100 \%$. Similarly for second variable temperature 9 membership functions are defined from T1 to T9 with temperature varying from $20^{\circ} \mathrm{c}$ to $40^{\circ} \mathrm{c}$ [11].

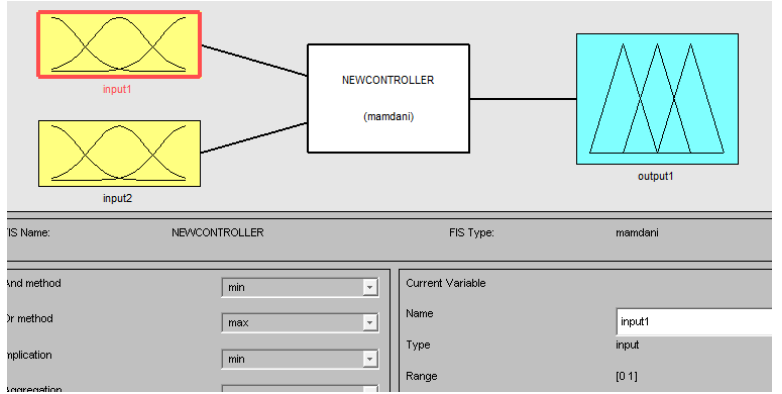

Fig. 7. Fuzzy inference system of proposed controller.

There are two input variables temperature and Rate of change of temperature each of them having 7 membership functions namely, NB - Negative Big; NM - Negative Medium; NS Negative Small; PB - Positive Big; PM - Positive Medium, PS - Positive Small, ZO- Zero value. With the help of these input variable 49 rules were defined given below

1. If $E=N B$ and $E R=N B$ Then $H=P B$

2. If $E=N B$ and $E R=N M$ Then $H=P M$

3. If $E=N B$ and $E R=N S$ Then $H=P B$

4. If $\mathrm{E}=\mathrm{NB}$ and $\mathrm{ER}=\mathrm{Z} 0$ Then $\mathrm{H}=\mathrm{PB}$

$\ldots$

47. If $E=P B$ and $E R=P S$ Then $H=N B$

48. If $E=P B$ and $E R=P M$ Then $H=N B$

49. If $\mathrm{E}=\mathrm{PB}$ and $\mathrm{ER}=\mathrm{PB}$ Then $\mathrm{H}=\mathrm{NB}$

\begin{tabular}{|c|c|c|c|c|c|c|c|}
\hline$>_{\mathrm{ER}} \mathrm{E}$ & NB & NM & NS & $\mathrm{ZO}$ & PS & $\mathrm{PM}$ & $\mathrm{PB}$ \\
\hline NB & $\mathrm{PB}$ & PM & PB & $\mathrm{PB}$ & PM & PS & $\mathrm{ZO}$ \\
\hline NM & $\mathrm{PM}$ & PB & $\mathrm{PM}$ & $\mathrm{PM}$ & PS & $\mathrm{ZO}$ & NS \\
\hline NS & PB & PB & $\mathrm{PM}$ & PS & $\mathrm{ZO}$ & NM & $\mathrm{NM}$ \\
\hline $\mathrm{ZO}$ & PB & $\mathrm{PM}$ & PS & $\mathrm{ZO}$ & NS & NS & NB \\
\hline PS & $\mathrm{PM}$ & PM & $\mathrm{ZO}$ & NS & NM & NB & NB \\
\hline PM & PS & $\mathrm{ZO}$ & NS & NM & NM & NB & NB \\
\hline PB & $\mathrm{ZO}$ & NS & NM & NB & NB & NB & NB \\
\hline
\end{tabular}

The fuzzy controller surface and the output are shown in figure 8 and 9 respectively,

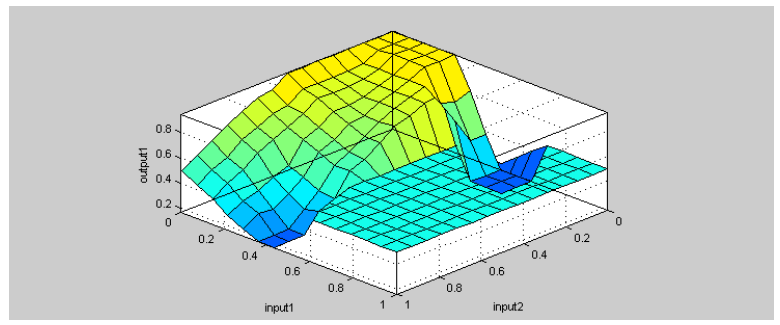

Fig. 8. Fuzzy surface of proposed controller

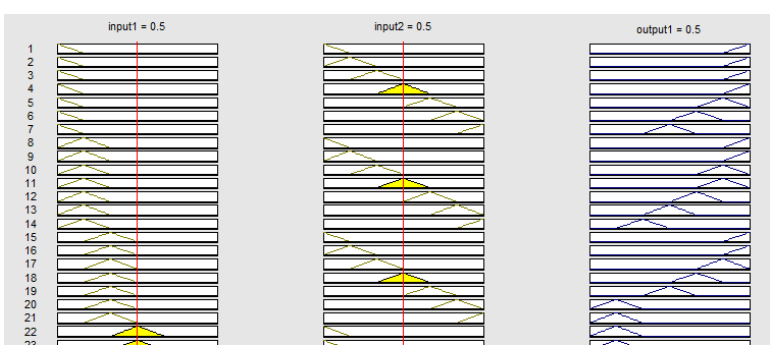

Fig. 9. Fuzzy rules of proposed controller 
In these cases, the Fuzzy Logic Controller block uses the S-function suffix to simulate the FIS. When we use fuzzy logic controller with rule viewer it shows the complete set of rules with Mux and Demux [12-14].

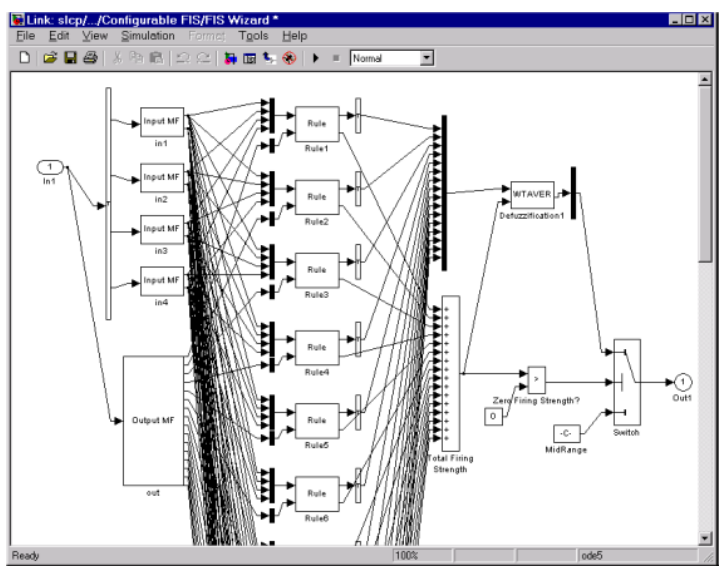

Fig. 10. Fuzzy controller result showing different rules.

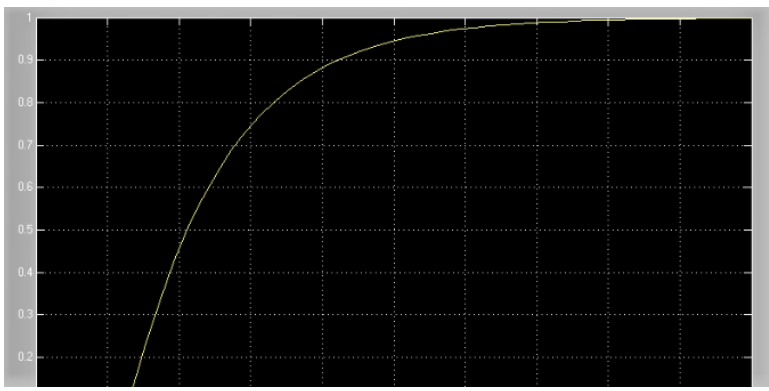

Fig. 11. Simulation result of proposed controller

\section{Conventional PID controller}

PID controller is most popular in industrial applications. But the parameter selection for the $\mathrm{Kp}, \mathrm{Ki}, \mathrm{Kd}$ gains is always a challenge. Many tuning algorithms were developed, but still it is a major pain to select particular algorithm for designing PID gain values for the particular system for a particular process control. Equation no (1) below [15] shows the mathematical description of a general PID controller

$u(t)=K_{p}\left(e(t)+\frac{1}{T_{i}} \int_{0}^{t} e(\tau) d(\tau)+T_{d} \frac{d e(t)}{d(t)}\right)$

Where $\mathrm{u}(\mathrm{t})$ is control signal applied to plant

$\mathrm{K}_{\mathrm{p}}$ is proportional gain

$\mathrm{K}_{\mathrm{i}}$ is Integral gain

$\mathrm{K}_{\mathrm{d}}=\mathrm{K}_{\mathrm{p}} * \mathrm{~T}_{\mathrm{d}}=$ Derivative gain

$\mathrm{T}_{\mathrm{i}}$ is integral time constant

$\mathrm{u}$ is the control signal \& e is control error

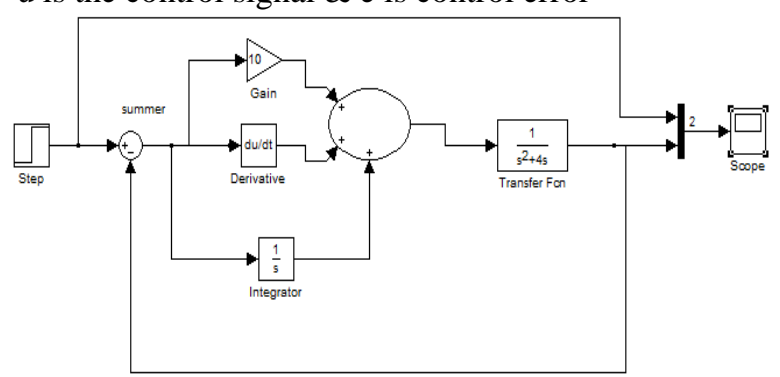

Fig. 12. Simulation setup for conventional PID controller
Figure 12 and 13 are showing the PID model and its corresponding response which belong to the instrument. From the response it is clear that there is huge peak overshoot and undershoot which causes the change in relative humidity that leads to the degradation in instrumental performance.

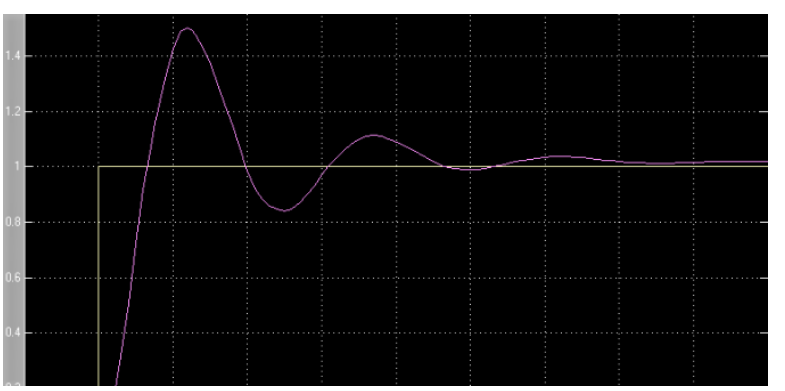

Fig. 13. Simulation setup for conventional PID controller

\section{E. Discussion on results}

This part of the research is dedicated to minimize the effect of input temperature fluctuation on the deviation in the value of relative humidity which was caused to degrade the instrumental performance. In the conventional PID controller controlled instrument there was very large peak overshoot.

The Simulink model of conventional PID controller includes $\mathrm{k}_{\mathrm{p}}=10, \mathrm{~K}_{\mathrm{i}}=1$ and $\mathrm{k}_{\mathrm{d}}=1$. The step response of this system shows first peak overshoot of around $67 \%$ and a finite amount of steady state error persists. The fuzzy PID controller is set as: It is functioning for two inputs temperature and its rate of change and output value as relative humidity. The output response shows though it is slower than conventional PID controller but peak overshoot is almost reduced to zero level so the effect of input temperature fluctuations will not be able to affect the relative humidity and the performance of the instrument will be improved substantially.

\section{CONCLUSION AND FUTURE WORK}

In the second part of the research, the conventional PID controller has been used for relative humidity controller. With the advancement in technologies fuzzy logic based intelligent controller is introduced for similar applications. The performance of both the controller is evaluated and compared against each other and following inferences which made are as follow:

1) Even though the PID controller based system produces response with less delay, rise time and settling time but in this system has many oscillation with large overshoot of approximately $67 \%$ which causes the degradation in instrumental performance.

2) To suppress these oscillations fuzzy logic controller is proposed to use. From the result it can be easily observed that this controller can efficiently reduce the oscillations and produces smooth response.

The future scope regarding this research field could be in spite of using triangular membership other membership functions which are more closer to the characteristics of nonlinear systems like Gaussian, bell shaped membership function or even two dimensional membership function can be used for this analysis. Beside this in spite of using simple fuzzy controller an intelligent fuzzy PID controller can be used in 
which for selection of proportional, integral and derivative gain some optimized algorithm will needed to be proposed which give better result.

\section{ACKNOWLEDGMENT}

We are highly thankful to the Belz Instruments pvt. Ltd. Faridabad (Haryana) - India for their whole hearted support and for providing us the facility at their workplace to establish experimental study and to procure the experimental data from their instrument named RH generator.

\section{REFERENCES}

[1] Verma, Avnesh ; Tiwari, Vishnu Anand; (June 2013): Optimum Fuzzy Based Approach to Improve the Instrument's Performance Affected by Environmental Conditions.: Serbian Journal of Electrical Engineering. 10(2), pp 309-318.

[2] Mohanraj, M.R.; Balamurugan, M; Suresh, V. P; Gobu, R. ; (2016): Design of Air-Conditioning Controller by using Mamdani and Sugeno Fuzzy Inference Systems: South Asian Journal of Engineering and Technology 2(16), pp. 7-16.

[3] Tarun Kumar Das, Yudhajit Das (2013): Design of A Room Temperature And Humidity Controller Using Fuzzy Logic: American Journal of Engineering Research (AJER), 02(11), pp-86-97.

[4] Akpado, K.A. ; Nwankwo, P. N. ; Onwuzulike, D.A. ; Orji, M.N. (Aug 2018): A Hybrid Approach For Air Conditioning Control System With Fuzzy Logic Controller: International Journal of Engineering and Applied Sciences (IJEAS), 5(8), pp. 1-50.

[5] Ramesh, K.: Kesarkar, A. P. : Bhate, J. : Venkat Ratnam, M. Jayaraman, A.(2015): Adaptive neuro-fuzzy inference system for temperature and humidity profile retrieval from microwave radiometer observations, : Atmos. Meas. Tech. pp. 369-384.

[6] Zadehbagheri, O. ; Eskandari, H. ; Rezazadeh, A. ; Sedighizadeh, M., (June,2014): HUMIDITY PROCESS CONTROLLING USING

\section{AUTHORS PROFILE}

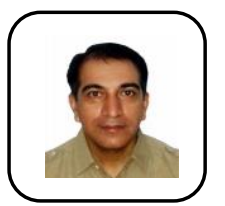

Avnesh Verma, is working in the Dept of Instrumentation in Kurukshetra University, Haryana India. He is BE, M.Tech (Electrical) and PhD in FPGA based optimal Design and its application. He has Published \& Presented 29 papers in International/National Journals/Conferences. He has 22 years of experience in teaching and research.

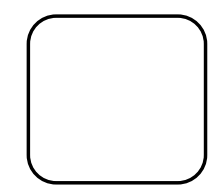

Vishnu Anand Tiwari, has done M. Tech, (Instrumentation) from NIT, Kurukshetra Haryana India. $\mathrm{He}$ has published papers in International/National Journals/Conferences.
FUZZY TYPE-1 AND TYPE-2 WITH PID CONTROLLER, International Journal on "Technical and Physical Problems of Engineering" (IJTPE), 19(6),(2), pp 117-121.

[7] Zadeh, Lofi A; Berkeley, CA; (1995): Fuzzy logic toolbox User's guide the MathWorks.

[8] Zadeh, L.A (1965), Fuzzy sets, Information and control pp 338-353, 1965

[9] Bentley, Robin E.: (December 21, 1998), Handbook of Temperature Measurement: Temperature and humidity ., Volume 1 Publisher: Springer; 1 edition.

[10] The Effect of Relative Humidity on Ozone Production by Corona Discharge in Oxygen or air ,A Numerical Simulation - Part II : Air, ( 2008) pp 41-64.

[11] Pedricz, W. e; Gomide, F.(1998): Introduction to fuzzy sets, Analysis and Design, Bradford, Imprints, Cambridge .

[12] Mary, P. Melba; Marimuthu, N.S. (2009): Design of self-tuning fuzzy controller for the control of an unknown industrial process,: IET Control Theory Appl., 3, pp. 428-436.

[13] Zhou, Hongfu; (2007): Simulation on Temperature Fuzzy Control in Injection Mould Machine by Simulink,: Guangdong Provincial Science and Technology Founding of China.

[14] A Practical Guide to Model Fuzzy Inference Systems using MATLAB and Simulink, Pablo Gomez, Florida International University, Department of electrical and computer Engineering

[15] Korkmaz, Mehmet; Aydoğdu, Ömer; Doğan Hüseyin (2012): Design and Performance Comparison of Variable Parameter Nonlinear PID Controller and Genetic Algorithm Based PID Controller, IEEE. 